\title{
The influence of size and chemical additives on the fabrication of micropattern nanocellulose films
}

Christine Browne, Jin Chyuan Lim, Wei Hann Sin, Gil Garnier, Warren Batchelor*

Bioresource Processing Research Institute of Australia (BioPRIA), Department of Chemical Engineering, Monash University, Clayton, VIC 3800, Australia

Number of pages: 11

Number of figures: 9

Number of tables: 4 


\section{Supporting Information}

\section{Mould Production}

Photolithography and deep reactive ion etching (DRIE) were used to create moulds with welldefined channels of widths $5,10,50,100,250$ and $500 \mu \mathrm{m}$ in width and depths of 6,12 and 18 $\mu \mathrm{m}$. The calculated aspect ratio (channel depth/width) of the channels vary between 0.012 and 3.6 and are shown in Table S1.

Table S1 - The calculated aspect ratio of the micropattern channels.

\begin{tabular}{|l|l|l|l|}
\hline \multirow{2}{*}{$\begin{array}{l}\text { Channel width } \\
(\boldsymbol{m})\end{array}$} & Depth $(\boldsymbol{\mu m})$ & $\mathbf{1 2}$ & $\mathbf{1 8}$ \\
\cline { 2 - 4 } & $\mathbf{6}$ & 0.024 & 0.036 \\
\hline $\mathbf{5 0 0}$ & 0.012 & 0.048 & 0.072 \\
\hline $\mathbf{2 5 0}$ & 0.024 & 0.12 & 0.18 \\
\hline $\mathbf{1 0 0}$ & 0.06 & 0.24 & 0.36 \\
\hline $\mathbf{5 0}$ & 0.12 & 1.2 & 1.8 \\
\hline $\mathbf{1 0}$ & 0.6 & 2.4 & 3.6 \\
\hline $\mathbf{5}$ & 1.2 & & \\
\hline
\end{tabular}

A photomask was fabricated at the Minnesota Nano Center and was designed with the use of KLayout (version 0.25.4). The SU 82002 photoresist was spun (Laurell Technologies spin coater, WS-650-8B) onto the silicon wafers to give a resultant thickness of approximately 2.5 $\mu \mathrm{m}$. The photoresist exposure (UV flood source ABM-USA) was performed to a delivered energy of $100 \mathrm{~mJ} / \mathrm{cm}^{2}$. Prior to exposure, a soft bake of 2 minutes at $95{ }^{\circ} \mathrm{C}$ was performed and after the exposure the post exposure bake was conducted at $95^{\circ} \mathrm{C}$ for 3 minutes. Development of the wafer was conducted in SU 8 developer for 1 minute, the wafer was then rinsed with 2propanol and dried under nitrogen. 
This wafer was then placed within a PlasmaLab 100 ICP380 (Oxford Instruments) to complete the DRIE processing until the desired channel depths were reached. The wafer was subsequently cleaned in hot sulfuric acid $\left(130^{\circ} \mathrm{C}, 10\right.$ minutes $)$. The wafer was cleaned with Milli-Q water and dried under nitrogen. To remove any remaining SU 8 photoresist, the wafer was subjected to an $\mathrm{O}_{2}$ plasma for 10 minutes.

\section{Microscope Objectives for Surface Analysis}

Table S2 - Summary of microscope objective selection and dimensions of the inspection area for the various sample channel widths

\begin{tabular}{|c|c|c|}
\hline Channel width $(\boldsymbol{\mu m})$ & $\begin{array}{l}\text { Microscope } \\
\text { objective }\end{array}$ & $\begin{array}{l}\text { Dimensions of } \\
\text { inspection area }(\boldsymbol{\mu m})\end{array}$ \\
\hline 250 and 500 & $10 \times$ & 1280 \\
\hline 50 and 100 & $50 \times$ & 256 \\
\hline 5 and 10 & $100 \times$ & 128 \\
\hline
\end{tabular}


Table S3 - Summary of the design width, measured width and depth, difference between the design and measured widths and the resultant channel shape for the laser cut channels.

\begin{tabular}{|l|l|l|l|l|}
\hline $\begin{array}{l}\text { Design width } \\
(\boldsymbol{\mu m})\end{array}$ & $\begin{array}{l}\text { Measured width } \\
(\boldsymbol{\mu m})\end{array}$ & $\begin{array}{l}\text { Measured depth } \\
(\boldsymbol{\mu m})\end{array}$ & $\begin{array}{l}\text { Difference } \\
\text { between } \\
\text { design and } \\
\text { measured } \\
\text { width }(\%)\end{array}$ & Channel shape \\
\hline 100 & 160 & 31 & 60 & V-shape \\
\hline 200 & 370 & 193 & 85 & V-shape \\
\hline 300 & 480 & 275 & 60 & V-shape \\
\hline 400 & 590 & 314 & 48 & Round bottom \\
\hline 500 & 660 & 343 & 32 & Round bottom \\
\hline 1000 & 1180 & 363 & 18 & Square bottom \\
\hline
\end{tabular}

\section{Demonstration of conformation regimes}
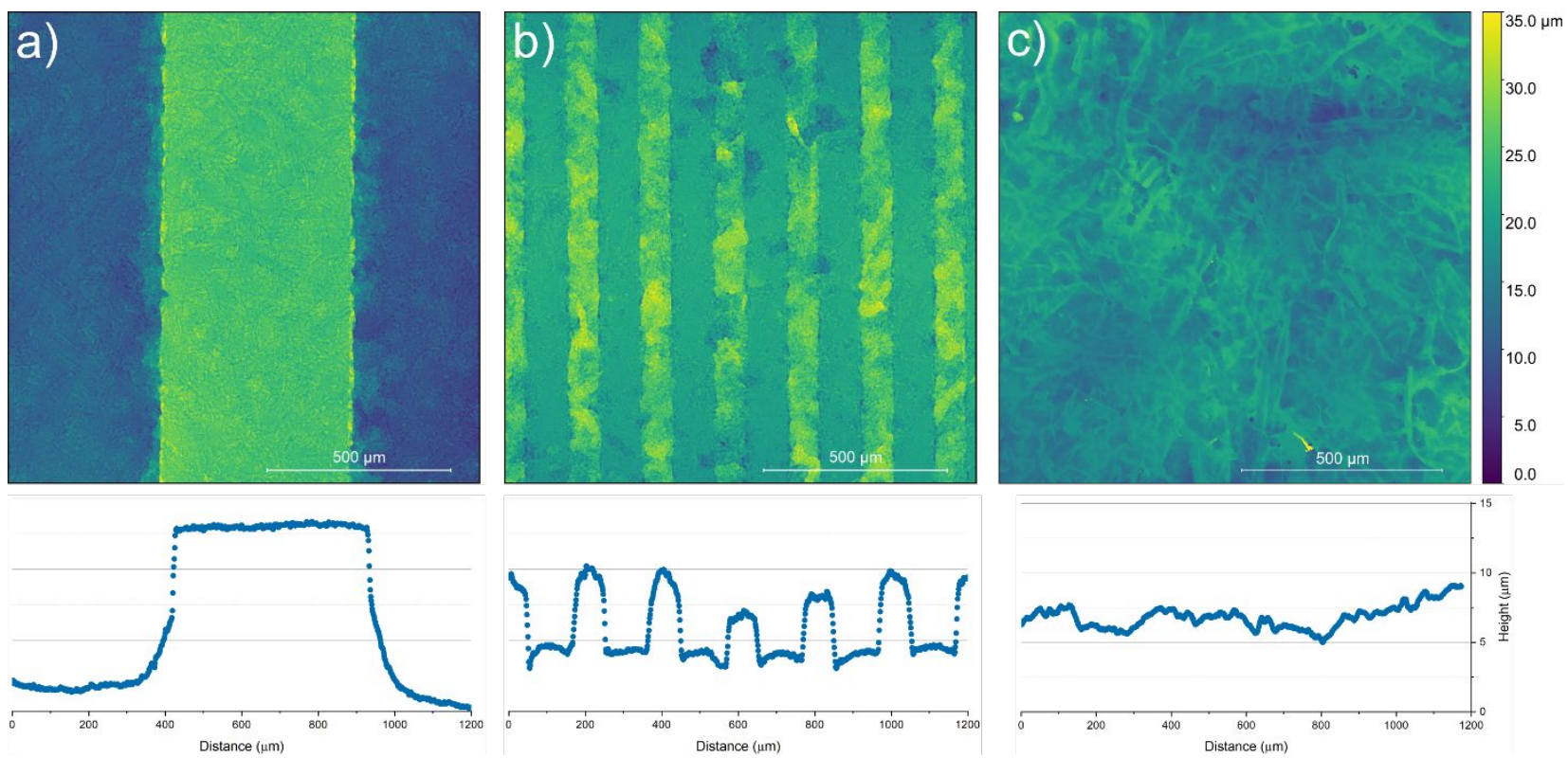

Figure S 1 - Optical profilometry images and height profiles (mean value of each vertical line) for the 50/50 CNC systems demonstrating the various conformation regimes. All mould channels depths were $12 \mu \mathrm{m}$ a) full conformation with $500 \mu \mathrm{m}$ width channels; b) partial conformation with $100 \mu \mathrm{m}$ width channels and c) no conformation with $5 \mu \mathrm{m}$ width channels (region selected had no visual channels). 

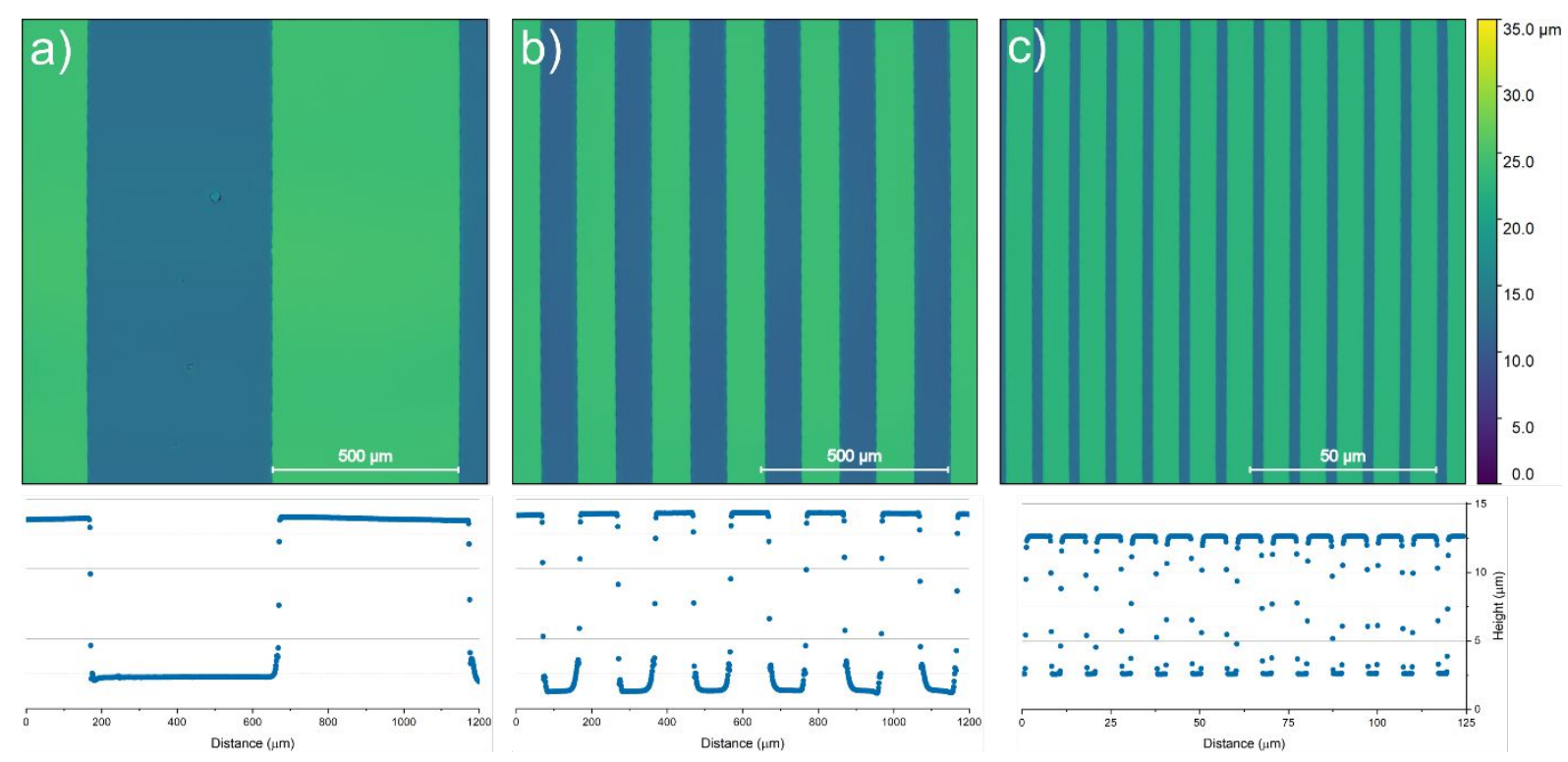

Figure S 2 - Optical profilometry images and height profiles (mean value of each vertical line) for the silicon moulds. All mould channels depths were $12 \mu \mathrm{m}$ and channel widths of a) 500 $\mu \mathrm{m}$; b) $100 \mu \mathrm{m}$ and c) $5 \mu \mathrm{m}$.

\section{Photograph of moulds and 50/50 CNC film}
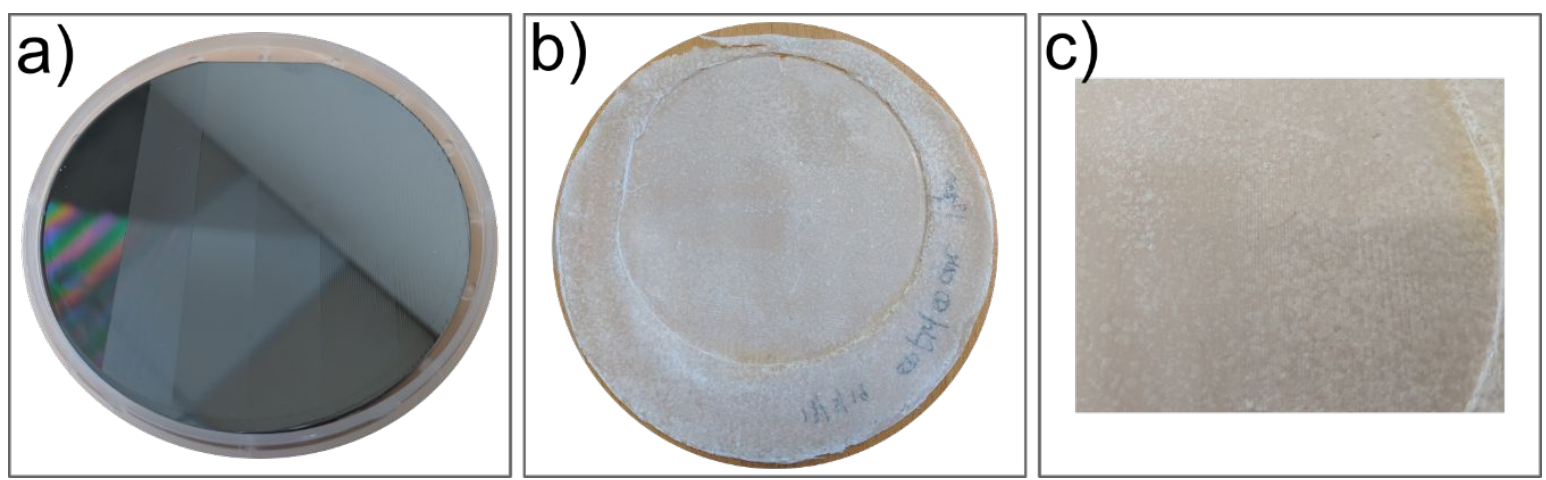

Figure S 3 - Photographs of a) silicon mould; b) entire micropatterned films removed from mould of the 50/50 CNC system; c) close up of micropatterns with channel widths of 100, 250 and $500 \mu \mathrm{m}$ visible. 


\section{Full data sets of the mould verse sample aspect ratio}

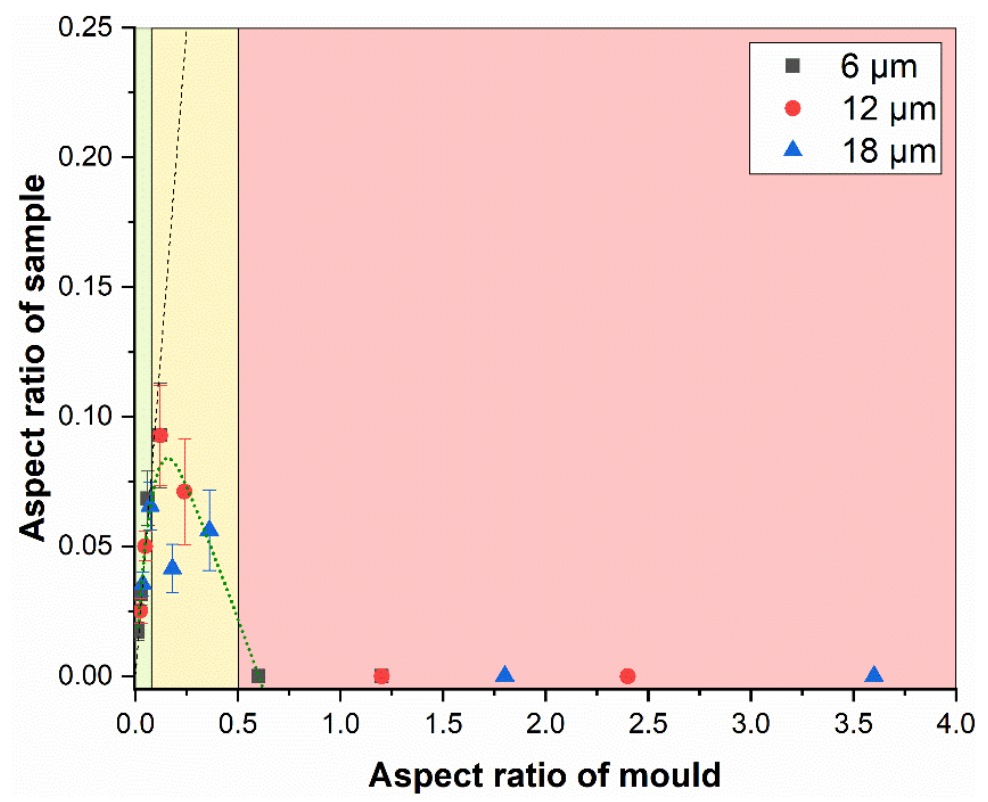

Figure S 4 - Aspect ratio of mould versus the measured aspect ratio of the sample for the 1.5 $\mathrm{wt} \%$ homogenised nanocellulose sheets. The data shown is for 6 (black squares), 12 (red circles) and $18 \mu \mathrm{m}$ (blue triangles) mould depths. A 1:1 line has been plotted to indicate the area where the mould and sample dimension match. The spline fit for this sample is shown by a green dotted line. The shaded areas correspond to the different conformation regimes which are from left to right full conformation (green), partial conformation (yellow) and no conformation (red).

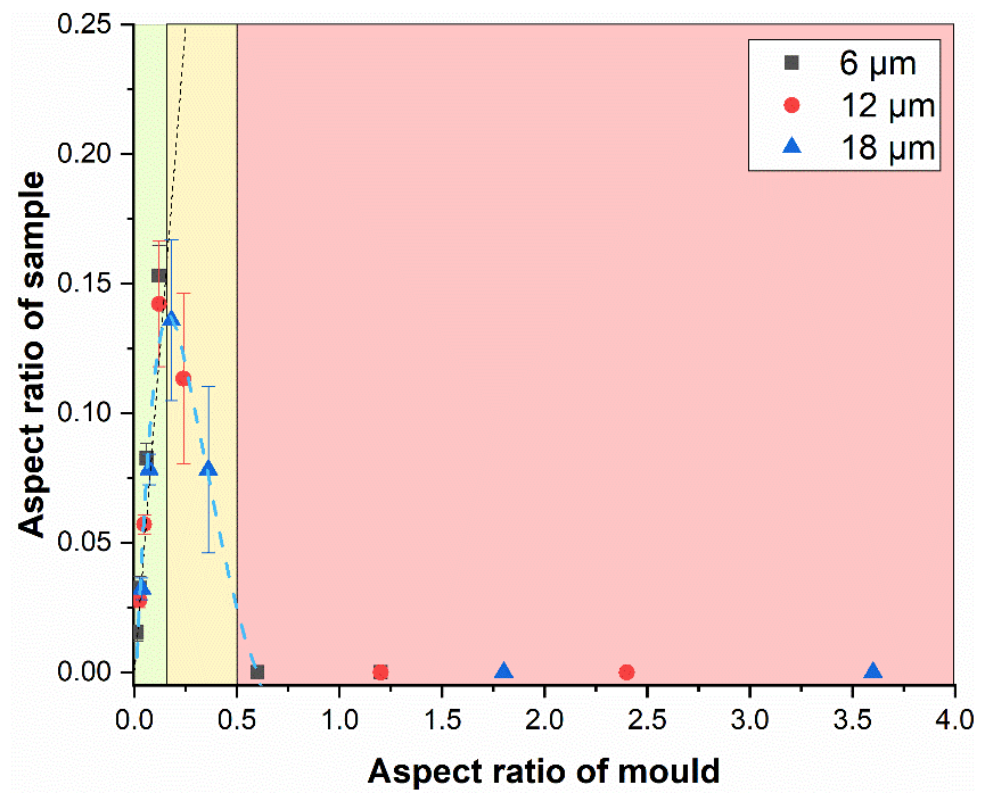

Figure S 5 - Aspect ratio of mould compared to the aspect ratio of the $1.5 \mathrm{wt} \% \mathrm{CMC}$ nanocellulose sheets. Mould depths of $6 \mu \mathrm{m}$ (black squares), $12 \mu \mathrm{m}$ (red circles) and $18 \mu \mathrm{m}$ 
(blue triangles) were used. The 1:1 line (dotted black) indicates where the mould and sample aspect ratios match. The spline fit for this sample is shown by a dashed blue line. Full conformation (green), partial conformation (yellow) and no conformation (red) are shown with the shaded areas.

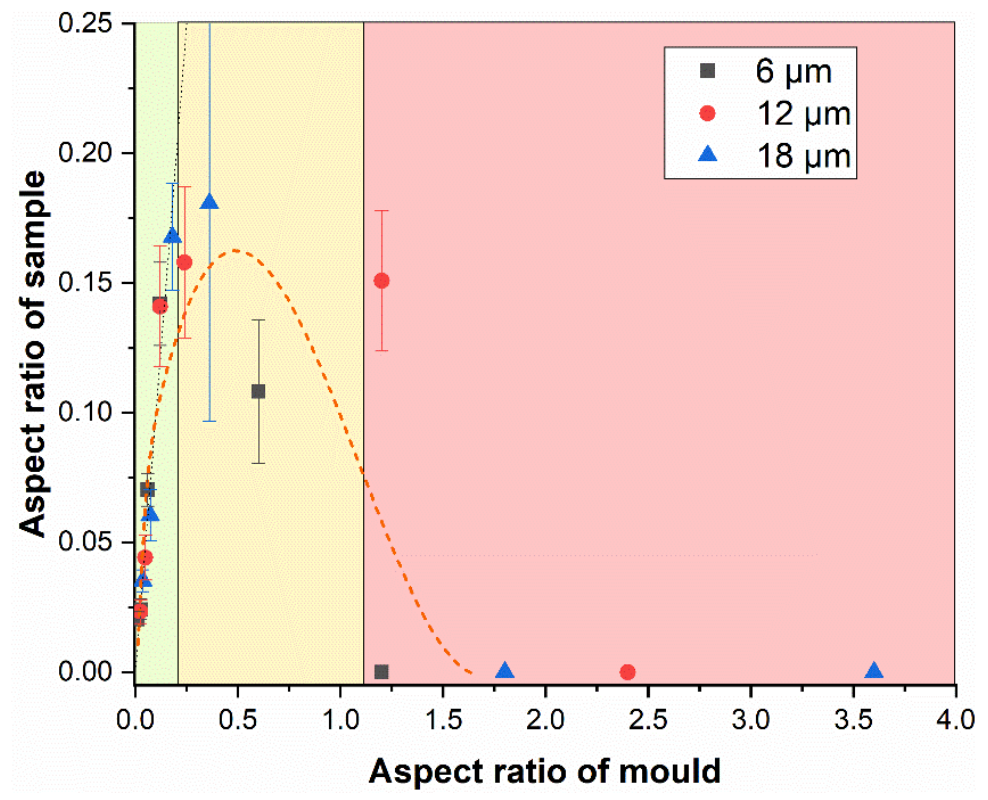

Figure S 6 - Aspect ratio of mould compared to the aspect ratio of the $1.5 \mathrm{wt} \% 80 / 20$ - CNC nanocellulose sheets. Mould depths of $6 \mu \mathrm{m}$ (black squares), $12 \mu \mathrm{m}$ (red circles) and $18 \mu \mathrm{m}$ (blue triangles) were used. The 1:1 line (dotted black) indicates where the mould and sample aspect ratios match. The spline fit for this sample is shown as a dashed orange line. Full conformation (green), partial conformation (yellow) and no conformation (red) are shown with the shaded areas. 


\section{Gel Point Determination}

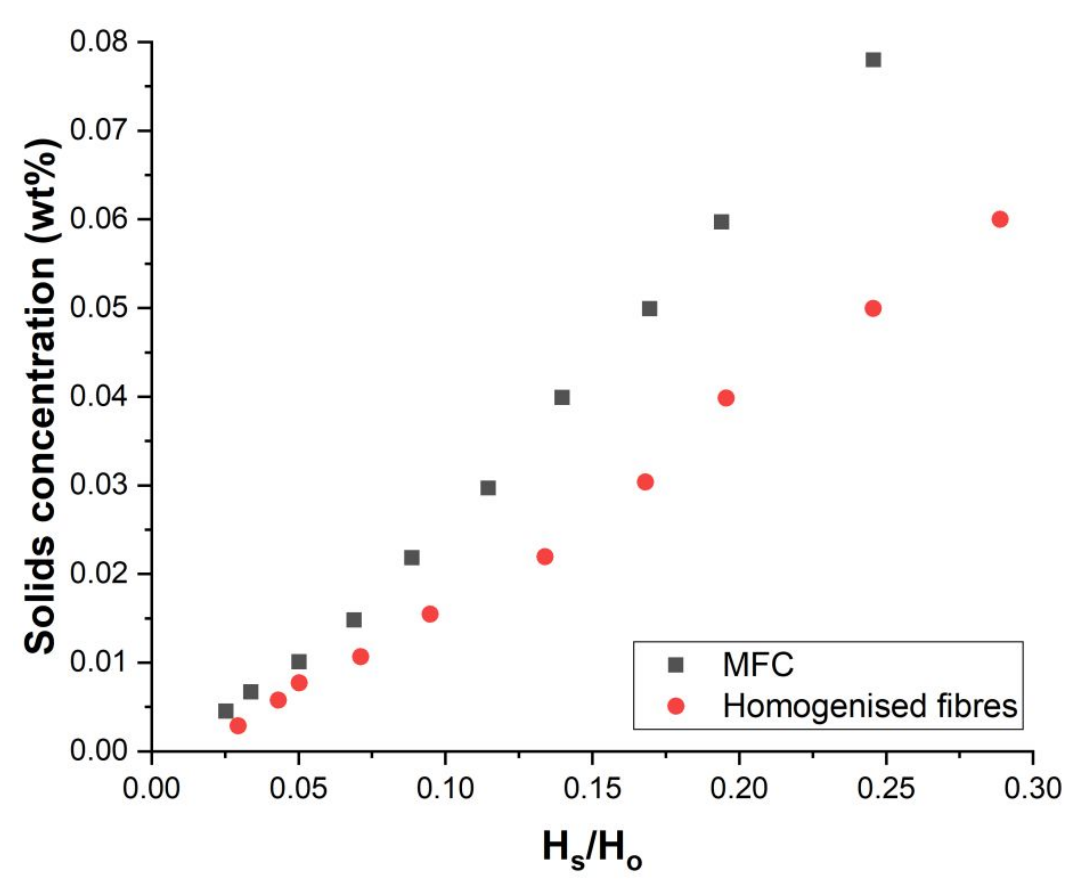

Figure $\mathbf{S} 7$ - Plot of $\mathrm{H}_{\mathrm{S}} / \mathrm{H}_{\mathrm{o}}$ verses the solids concentration of unmodified and homogenised nanocellulose fibres. The gel point of the fibre suspension was determined from this data. 


\section{$\underline{\text { Laser Cut Channels }}$}

Channel Depths with Varying Speed and Power

The power and speed of the laser were varied to understand the relationship between these parameters and the resultant etch depth within the laser cutting device. We also used two different paper sources, one was a light weight blotting paper and the other a heavy weight paperboard.

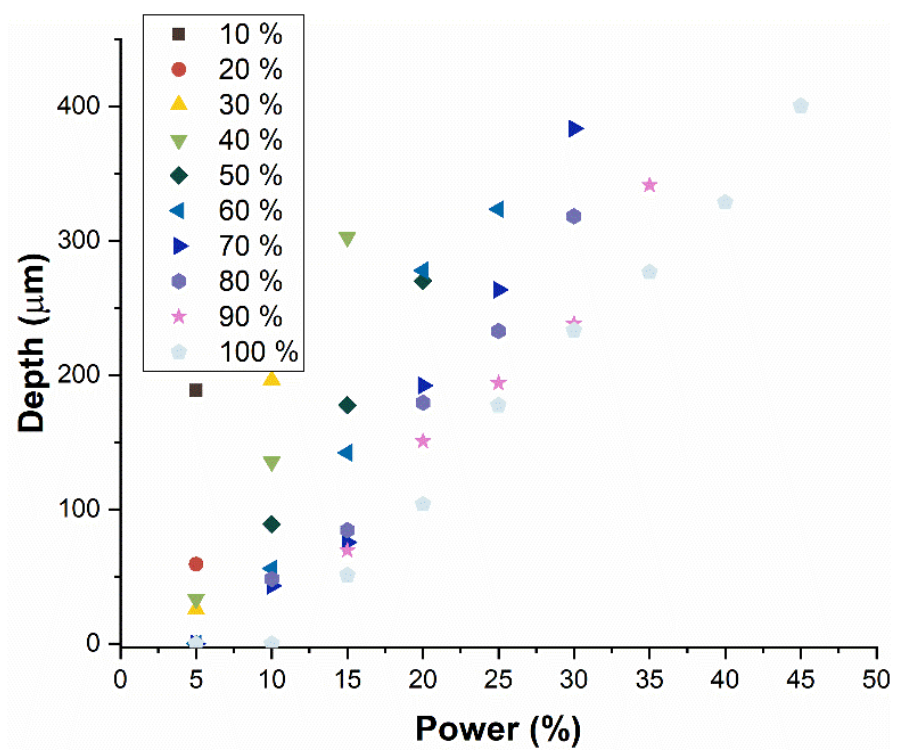

Figure S 8 - The measured etch depths achieved with blotting paper with respect to laser power and speed. The laser speeds used are presented within the legend. 


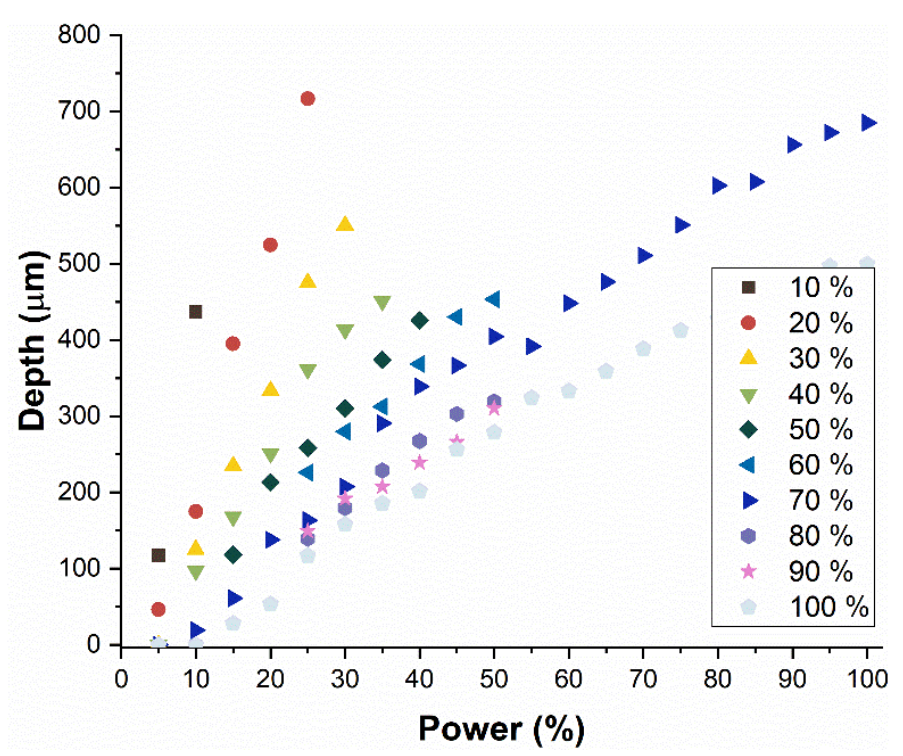

Figure S 9 - The measured etch depths achieved with paperboard with respect to laser power and speed. The laser speeds used are presented within the legend.

These results demonstrate for both types of paper used (Figure S6 and Figure S7), that with increasing power of the laser (expressed as a percentage of the available power) the etch depth increased. When the speed of the laser (expressed as a percentage of the maximum speed) increased the etch depth decreased as the laser was travelling faster across the surface and these trends have been shown previously in a variety of materials[1-3].

\section{Mass of Sample Removed During Laser Etching}

To calculate the paper density of both the paper sources eight $25 \mathrm{~mm}$ squares were cut with the laser cutter. The mass of these samples (analytical balance, Mettler Toledo, TLE) and the thickness (Lorentzen \& Wettre Micrometer 51, Stockholm, Sweden) were determined. These results allowed the paper density for each source to be calculated.

Table S4 - Results from the etching studies

\begin{tabular}{|l|l|l|}
\hline Parameter & Cardboard & Blotting Paper \\
\hline Mass (g) & $0.608 \pm 0.003$ & $0.164 \pm 0.002$ \\
\hline Thickness (mm) & $1.096 \pm 0.006$ & $0.466 \pm 0.005$ \\
\hline Mass/thickness (g/mm) & 0.55 & 0.35 \\
\hline Mass/volume (g/mm m $\left.^{3}\right)$ & $8.87 \times 10^{-4}$ & $5.64 \times 10^{-4}$ \\
\hline $\begin{array}{l}\text { Scaled mass/thickness with } \\
\text { respect to cardboard }\end{array}$ & 1 & 0.635 \\
\hline
\end{tabular}




\begin{tabular}{|l|l|l|}
\hline $\begin{array}{l}\text { Scaled mass/volume with } \\
\text { respect to cardboard }\end{array}$ & 1 & 0.635 \\
\hline
\end{tabular}

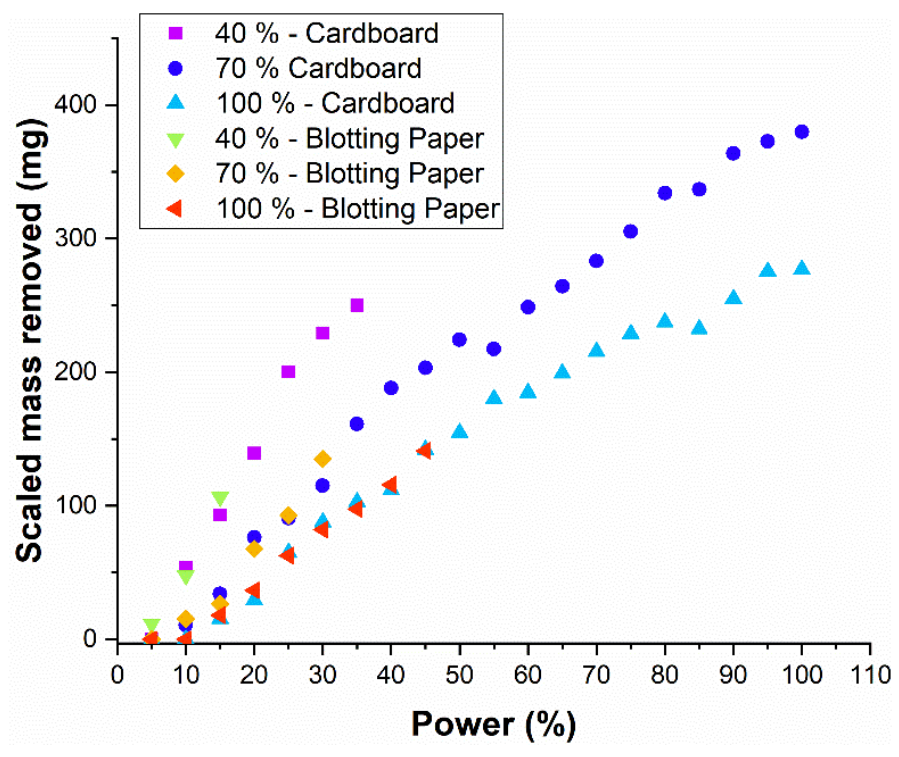

Figure S 10 - The calculated scaled mass removed for blotting paper and cardboard with respect to laser power and speed. Selected laser speeds of 40, 70 and 100\% are shown and listed within the legend.

The blotting paper typically had increased etch depths at the same laser settings when compared to the cardboard paper, which demonstrates that the type of paper used is also an important parameter. When the measured etch depths accounted for the density of each of the paper sources (results presented in Table S2) the scaled removed mass of both samples were similar as shown in Figure S8) for the same laser settings. This indicates that the higher density cardboard was more sensitivity to changes in both the laser speed and power, which allows finer control of the resultant etch depths. Also, the cardboard has a thickness of $1.096 \pm 0.006$ mm compared to the blotting paper thickness of $0.466 \pm 0.005 \mathrm{~mm}$, which makes the cardboard more suitable to be used within microfluidic devices[1].

Channels with widths of $100,200,300,400,500$ and $1000 \mu \mathrm{m}$ were then laser etched into the paperboard source. These parameters were chosen to mimic those achieved by the moulding process. Channels were typically slightly wider than the designed value and channel widths 
lower than $100 \mu \mathrm{m}$ were not possible with the laser cutter used within this study. Channels were created in both parallel and perpendicular to the laser travel direction. It was found that channels created perpendicular to the laser travel direction had a lower resolution, both in depth and width, due to the relative short amount of time the laser needed to be activated for cutting when compared to long time frames of the parallel direction. The perpendicular travel direction was selected for comparison as within a microfluidic device there would be channels in multiple directions. The laser power and speed settings were varied to determine the minimum resolution possible of the channel widths and depths.

\section{References}

[1] M. Naseri, G.P. Simon, W. Batchelor, Development of a Paper-Based Microfluidic System for a Continuous High-Flow-Rate Fluid Manipulation, Analytical Chemistry 92(10) (2020) 7307-7316.

[2] E.T. da Costa, M.S.F. Santos, H. Jiao, C.L. do Lago, I.G. Gutz, C.D. Garcia, Fast production of microfluidic devices by $\mathrm{CO} 2$ laser engraving of wax-coated glass slides, Electrophoresis 37(12) (2016) 1691-5.

[3] Z. Yan, X. Huang, C. Yang, Rapid prototyping of single-layer microfluidic PDMS devices with abrupt depth variations under non-clean-room conditions by using laser ablation and UVcurable polymer, Microfluidics and Nanofluidics 21(6) (2017). 